\title{
Depth-hoar growth rates near a rocky outcrop
}

\author{
E. M. Arons, ${ }^{1}$ S. C. Colbeck, J. M. N.T. Gray ${ }^{2}$ \\ ${ }^{1}$ U.S. Army Cold Regions Research and Engineering Laboratory, Hanover, New Hampshire 03755, U.S.A. \\ ${ }^{2}$ Institut für Mechanik, Technische Universität Darmstadt, Darmstadt, Germany
}

\begin{abstract}
Observations of slab-avalanche releases in alpine terrain have led to the hypothesis that rocky outcrops can influence the spatial distributions of temperature and heat flow in dry alpine snow covers and thus control the local distribution of depth hoar. We investigate the effects of terrain on crystal growth by using a two-dimensional finiteelement model of heat flow coupled with a model of crystal growth from vapor. We used the model to examine the influence of snow properties, terrain geometry and snow depth on this phenomenon. The effect is stronger in the early winter than in the late winter, because the rock has then had time to cool. In all cases, we found that depth-hoar growth occurs preferentially over the rock. This suggests that snow-pit investigations made over soil can be misleading if rocky outcrops are present.
\end{abstract}

\section{INTRODUCTION}

A dry-snow cover that is subjected to high temperatures and strong temperature gradients is often observed to develop crystals that are weakly bonded. These large, faceted crystals are commonly known as depth hoar. The weak bonding may give rise to mechanical failure and thus an avalanche, if the snow cover is on a sufficiently steep slope. In general, however, there is a complex and poorly understood relationship between the occurrence of depth hoar and the occurrence of an avalanche. For example, Akitaya (1974) reported that depth hoar can either decrease or increase the mechanical integrity of snow, and Arons (in press) has discussed the importance of gradients in snow strength for mechanical failure. Nonetheless, Jamieson and Johnston (1994), who analyzed the characteristics of snow covers associated with fatal avalanches in Canada during the period 1972-91, showed that nearly half of the fatal avalanches in that study are associated with snow composed of depth hoar in various stages of development.

Recently, we observed an avalanche fracture line that appeared to coincide with the emergence of a rocky outcrop from beneath a layer of soil. This observation motivated us to investigate the extent to which spatially varying, subsnow heat flow can control snow metamorphism. The importance of terrain features on slope stability has been recognized for a long time, although our understanding of the relationship is only beginning to evolve.

Our observation is consistent with other observations and measurements that imply that mechanical anchors introduce thermal perturbations that can change the mechanical properties of a layer of snow through metamorphism and make it more susceptible to failure. Logan (1993) analyzed eight avalanche accidents in Colorado during the period 1982-91 and found that spatial variation in snow thickness around rocks and vegetation may cause "tender spots" that are more vulnerable to failure than the remainder of the snow cover. He also made measurements of temp- erature and grain-size in the snow surrounding rocks and found that both are enhanced in those regions.

A full analysis of the distribution of the growth rates of depth hoar in a snow cover would require a detailed model that includes the effects of solar radiation, snow deposition, melting and the many non-linear features that arise from thermal properties that vary with temperature and metamorphic state (Jordan, 1991; Brun and others, 1992). However, a simple first-order analysis of the effects of heat-flow channeling by a rocky outcrop and the distribution of the growth rates of depth hoar requires only a microscopic model of crystal growth (e.g. Colbeck, 1983) and knowledge of the temperature distribution from the solution of an energy-balance equation.

Typically, snow is modeled as a one-dimensional layered medium. In those cases, the snow cover has a slab-like geometry with parallel top and bottom surfaces and a uniform depth. With spatially uniform boundary conditions, this geometry would give rise to one-dimensional heat flow. In many cases, the top surface is flat enough to warrant modeling as a plane. However, the geometry of the bottom surface, the snow-ground interface, may be irregular or undulating and thus give rise to two-dimensional heat flow as Logan's (1993) data suggest.

We simulated the effect of a non-uniform snow-ground interface on depth-hoar growth in the snow cover using PDE2D (vers. 5.2) partial differential equation solver (Sewell, 1993). Our calculations show that such an interface may cause channeling of heat through the more thermally conductive rock. If insulating soil is present between rock outcrops, the channeling is intensified. Thus, heat flow in and near a real outcrop is normally at least two-dimensional and spatially non-uniform. In local regions of higher heat flow and higher temperatures, more rapid snow metamorphism should be expected. We use the term terrainenhanced growth (TEG) to describe the effect of a simple rocky outcrop on the spatial distribution of rate of depthhoar growth in the snow cover. Under a uniform stress field, 
these microstructural changes would be expected to have a strong influence on the mechanical behavior of the snow cover but the quantitative effects on mechanical behavior are beyond the scope of this study.

\section{METHODS}

A two-dimensional model was constructed to investigate the effects of rock outcrops on crystal growth in dry-snow covers (Fig. 1). The model consists of three regions: the snow cover, the underlying bedrock and a thin layer of soil or organic material that separates the other two materials every where but at the outcrop. A finite-element method was used to solve the two-dimensional time-varying heat-flow equation

$$
\frac{\partial^{2} T}{\partial x^{2}}+\frac{\partial^{2} T}{\partial z^{2}}=\left(\frac{\rho C_{\mathrm{p}}}{k}\right)_{\alpha} \frac{\partial T}{\partial t}
$$

in which $T$ is temperature, $t$ is time, $\rho$ is density, $C_{\mathrm{p}}$ is specific heat, $k$ is thermal conductivity, $\alpha$ indicates the material at a point (snow, soil or rock), and $x$ and $z$ are the horizontal and vertical coordinates, respectively (Fig. 1). The thermal conductivity of snow was allowed to vary with snow density but not with temperature. In order to initialize the model so that the rock and snow had the desired temperature profiles early in the winter season, the model was run through many years to eliminate all transient effects except those due to the progression of the winter. We were not attempting to simulate the entire annual cycle, only to achieve the desired initial conditions for the wintertime simulations. Thus, we used a simple approach including a constant snow depth and density.

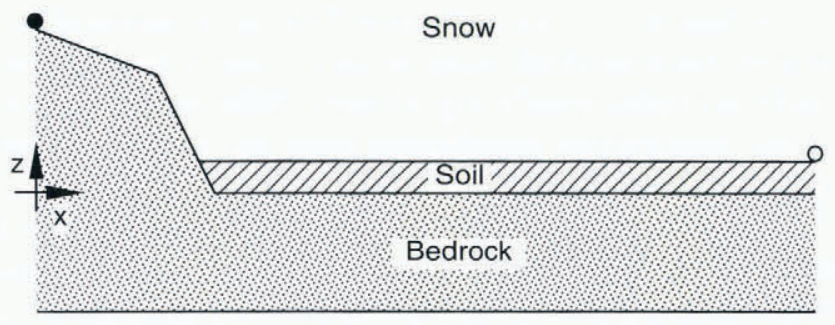

Fig. 1. The three-region model. "•" is the sampling location where the maximum absolute growth rate was observed $(1 \mathrm{~cm}$ above the peak of the outcrop). "O" is the location of the farfield growth site.

After solving for $T\left(x, z, t_{0}\right)$ and the temperature gradient $T^{\prime}\left(x, z, t_{0}\right)$, where $t_{0}$ is the time when we wish to examine the spatial distribution of growth rates, the radial graingrowth rate $\dot{a}$ was calculated following Colbeck (1983):

$$
\dot{a}\left(x, z, t_{0}\right)=\frac{D_{0}(T) C g}{\rho_{\mathrm{i}} a^{2}}\left|T^{\prime}\left(x, z, t_{0}\right)\right|\left(\frac{\partial \rho_{\mathrm{v}}}{\partial T}\right)_{\mathrm{eq}}
$$

in which $D_{0}$ is the diffusivity of water vapor in air, $C$ accounts for the shape and spacing of grains, $g$ is a measure of the thermal connectivity between the growing grain and the ice matrix, $\rho_{\mathrm{V}}$ is the density of water vapor, $\rho_{\mathrm{i}}$ is the density of ice and $a$ is grain radius. Although it appears that $\dot{a}$ depends on $a$, both $C$ and $g$ are proportional to $a$, so the radial growth rate is independent of grain-size.

The grain-growth rate $\dot{a}$, when calculated in this manner, may be thought of as the growth rate of a growing grain.
Grains that grow under a temperature gradient are known to grow at the expense of neighboring grains that are necessarily shrinking (e.g. Gubler, 1985). However, the evolution of distributions of grain-sizes in a dry-snow cover are not well known, so the role of shrinking grains has been ignored to allow a qualitative analysis of the effect of terrain on grain growth in snow.

A steady periodic solution of Equation (1) was obtained using a sinusoidally varying air temperature above the upper surface with a period $(\tau)$ of 1 year and zero normal heat flux at the bottom and side boundaries. The lateral boundaries were thus considered planes of symmetry and the lower boundary, at $\mathrm{z}=-50 \mathrm{~m}$, was well below the skin depth of the seasonal temperature oscillations at the surface. Although there is some geothermal heat flux at this depth, it is very small compared to the seasonal effect near the surface and does not account for the accelerated grain growth described here. The accelerated grain growth is due primarily to the heat stored in the ground over the summer, which is why it is very important to get a realistic temperature profile at the start of the winter season.

The top boundary condition was based on Newton's cooling law (Bird and others, 1960, p.391), which is commonly used to model heat flux across the interface between a solid and an adjacent fluid (i.e. snow cover and the wellmixed air flowing above it). This approach requires the vertical heat flux at the surface of the snow to match the heat flux that would arise from the temperature difference between the air and the top surface of the snow. The top boundary condition is thus given by

$$
\left.q_{z}\right|_{\text {surf }}=-50\left(T_{\text {surf }}-T_{\text {air }}(t)\right)
$$

where $T_{\text {surf }}$ is the solution $T$ at $z=z_{\text {surf }}$ for any $x$ and $t$. The heat-transfer coefficient 50 was chosen to cause heat exchange with the snow cover as judged by the results of Gray and others (1995). It gives the desired temperature effect at the skin depth in the snow-rock system. Subsequent computations showed that the results are remarkably insensitive to the value chosen, since increasing the coefficient decreases the temperature difference and the heat flow is affected very little.

The air temperature, $T_{\text {air }}$ is given by

$$
T_{\text {air }}(t)=22 \times \cos \left(\frac{2 \pi t}{\tau}+\pi\right)
$$

which gives a minimum daily mean temperature of $-22^{\circ} \mathrm{C}$. A diurnal temperature cycle could have been added to the annual cycle but the frequency of the diurnal signal is so high that it contributes little to the energy balance on the time-scale of interest when the rock outcrop is completely covered by snow (Gray and others, 1995).

The effects of changing the temporal, physical and spatial parameters in this study are most easily seen by comparing model results to an arbitrarily chosen standard. We chose a moderately dense, well-bonded, mid-winter snow cover $0.9 \mathrm{~m}$ thick. The standard-model ground cover is a thin, dry, sandy soil that would also correspond to a thin organic soil overlain by a thin layer of dry grass. The bedrock is unweathered granite which is continuous with a bouldersized outcrop that protrudes through the soil and into the snow cover. Characteristics of the standard model are shown in Table 1.1.

The rates of crystal growth are normalized to the growth rate calculated for a point $2 \mathrm{~cm}$ above the soil sur- 
Table 1. Properties and results of the standard model

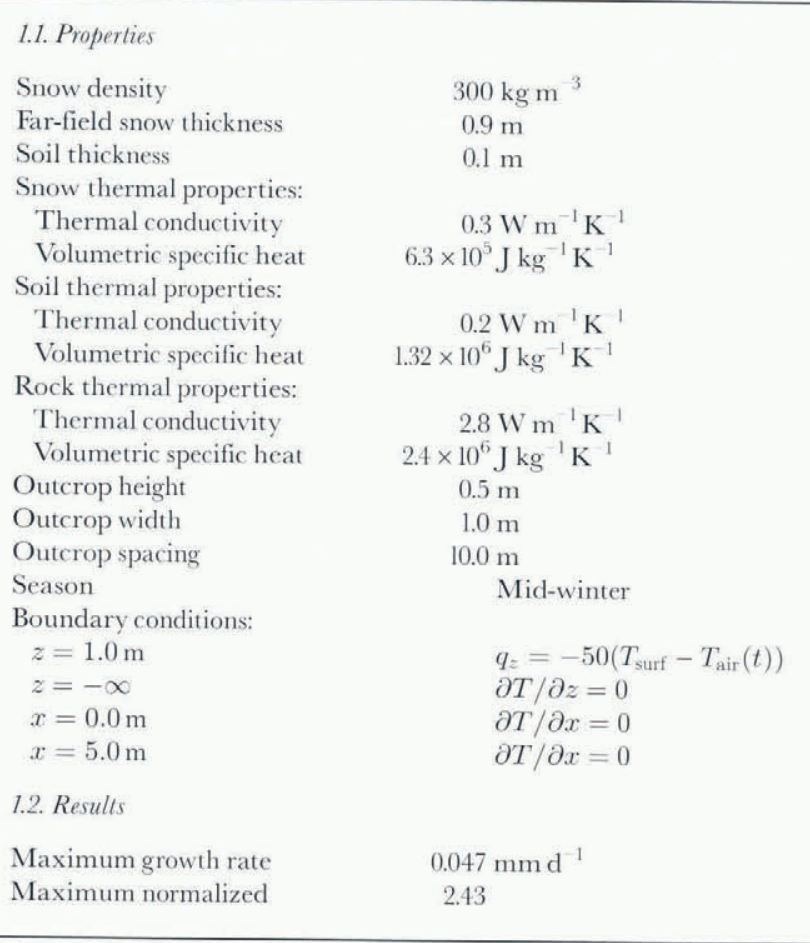

face and $200 \mathrm{~cm}$ away from the center of the rock. The normalized growth rate (NGR) represents the potential for crystal growth and is defined as

$$
\operatorname{NGR}(x, z)=\frac{\dot{a}(x, z)}{\dot{a}(x=200 \mathrm{~cm}, z=12 \mathrm{~cm})} .
$$

For the standard model, $200 \mathrm{~cm}$ is effectively an infinite distance from the rock outcrop. The NGR was always found to be greatest just above the peak of the rock and its value at that location was used to evaluate the importance of the phenomenon for varying sets of geometric and thermal parameters. This value is referred to as TEG, the maximum effect of terrain enhancement or the maximum value of NGR, and is defined as

$$
\mathrm{TEG}=\frac{\dot{a}(x=0 \mathrm{~cm}, z=51 \mathrm{~cm})}{\dot{a}(x=200 \mathrm{~cm}, z=12 \mathrm{~cm})} .
$$

It is important to note that this two-dimensional model is Cartesian and therefore assumed to extend to infinity in the direction normal to the plane of the solution space. On the scale of the snow cover, the rock peaks may therefore be viewed as infinite line sources of heat flux. As such, the temperature should decay in proportion to $1 / r$, where $r$ is the distance from the peak. In Nature, the rocks may behave more like point sources and therefore give rise to a $1 / r^{2}$ temperature decay. If this is the case, the rocks in our model will begin to interact with each other at a greater distance than hemispherical rocks and thus the temperature fields surrounding more realistic rocks would not interact until the rocks were closer together.

A useful comparison may be made with the field data of Logan (1993). It is apparent that strong lateral temperature gradients arise when the top of a rock is directly exposed to the atmosphere. The smaller albedo and greater thermal skin depth of the rock (Gray and others, 1995) allows diurnal heating cycles to have a stronger influence on the two-dimensional snow-temperature distribution in the vicinity of the rock. Logan's data suggest that these effects would tend to increase horizontal temperature gradients and therefore TEG. Our model does not include the effects of rocks that emerge from the snow but, since the snow depth is always least over the rock, it does describe the effect of replacing snow with more conductive rock. Thus, the effect we get is due to both the reduced thickness of the snow over the rock and the increased conductivity of the rock.

\section{RESULTS}

The model results predict that TEG occurs under a variety of conditions that might be observed in natural alpine snow covers. The magnitude of the effect depends on the time of year, the physical properties of the snow, soil and rock, the thickness of the snow layer and the dimensions of the rock. Standard output for all models includes two-dimensional fields of temperature, temperature gradient, crystal-growth rate and NGR. The output from the standard model (Table 1.2; Fig. 2) shows the effect of a rock of this geometry on the
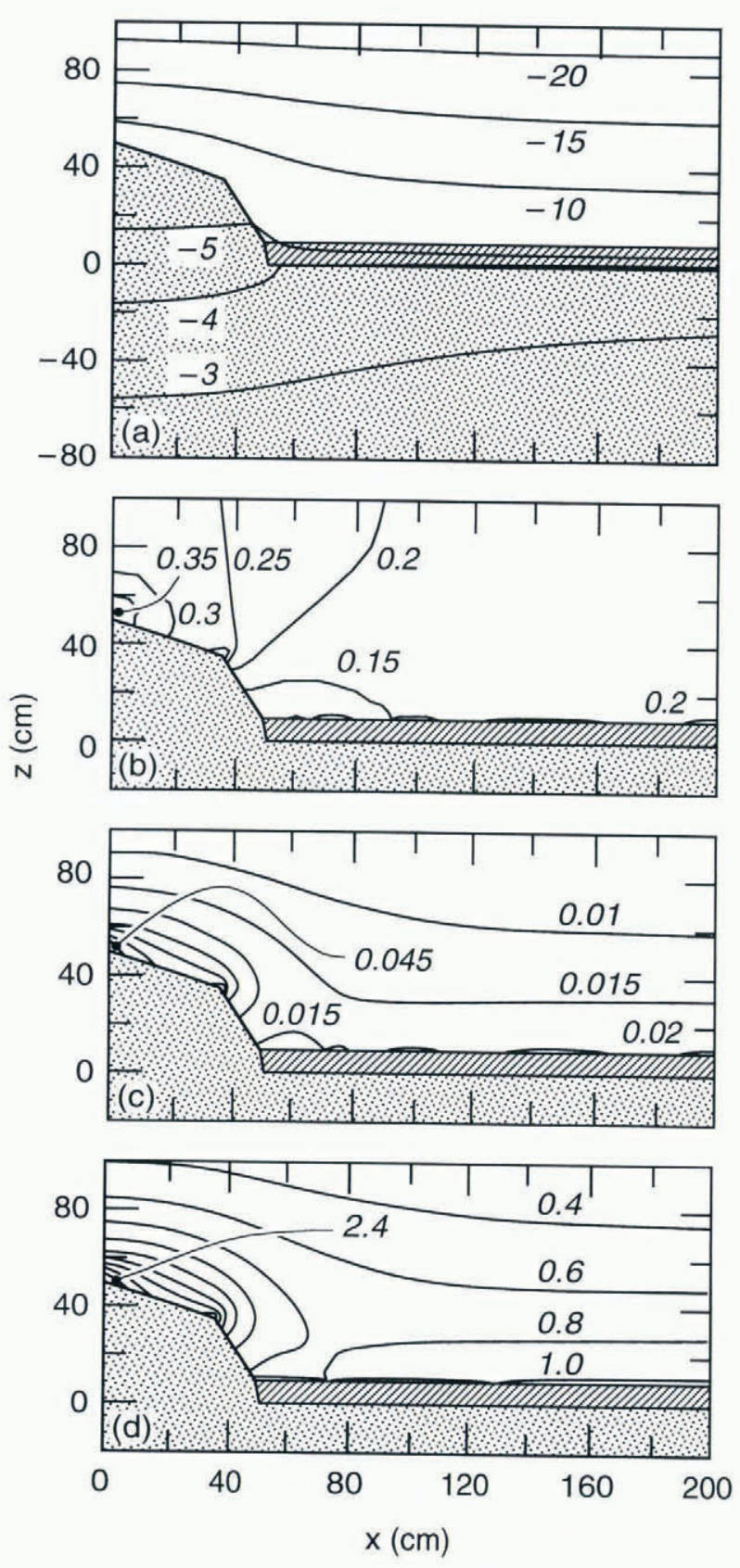

Fig. 2. The output from the standard, or mid-winter, model. (a) Temperature, (b) temperature gradient, (c) growth rate and (d) NGR. 
heat flow. The cold mid-winter atmosphere is able to draw more heat from the outcrop than from the surrounding region, because of the thinning of the snow cover over the rock and the difference in thermal storage and conductivity between the rock and the overlying snow. This is indicated by temperature contours, showing that heat is funneled towards the peak of the rock outcrop. Further evidence of this effect is the close spacing of the temperature contours above the rock peak due to the higher temperature gradient at that point. Finally, the temperatures in the snow overlying the rock peak are warmer than those at a similar depth far from the peak. It is the combination of elevated temperature and temperature gradient that enhances crystal growth on the granular scale. However, depth hoar will not necessarily form even with enhanced growth rates. The rule-of-thumb states that depth hoar forms only at temperature gradients above $0.1{ }^{\circ} \mathrm{Cm}^{-1}$ in low-density snow and at even higher temperature gradients in snow of higher densities. It would, however, form above the rock in all of the examples given here but not always over the soil. In higher-density snow, where larger temperature gradients are required, it would form in fewer of the examples.

The temperature gradients are highest at the snow-rock interface at the peak of the outcrop and decay almost radially away from the peak (Fig. 2b). A minimum in the snow-temperature gradient is exhibited at the foot of the outcrop where it begins to slope up from the horizontal bedrock underlying the soil. This is due to the influence of the highly conducting rock that borders that region of snow and reduces local temperature differences.

Using Equation (2), the calculated crystal-growth rates (Fig. 2c) show a maximum immediately above the rock peak. The calculated maximum absolute growth rate for the standard model is $0.047 \mathrm{~mm} \mathrm{~d}^{1}$. Starting with a grain of $0.2 \mathrm{~mm}$ diameter, this growth rate would produce a grain of $1.5 \mathrm{~mm}$ diameter after 2 weeks. Given the properties of the standard model, that is a reasonable estimate and NGR (Fig. 2d) is highest at the rock peak, as expected. It reaches more than 2.4 and decays in the far field to 1 as it must. A slight dip in the value of the NGR is observed near the foot of the outcrop due to the diminished temperature gradients in that region.

\section{SEASONAL EFFECTS}

To examine the effects of periodically varying mean air temperature, we investigated an "early winter" model and a "late-winter" model (Table 2.1). The former is based on the temperature profile 60 days before the air temperature minimum and the latter is based on the profile 60 days after that minimum. The realism of this simulation is limited by the fact that we maintain a constant snow depth throughout the winter. While this has little effect late in the winter, when the snow depth may well be the same as the mid-winter depth, it does affect the early winter results, since snow depth is normally less during that period. The effect of a thinner snow cover early in the winter would be to allow more heat loss and more rapid cooling, thus enhancing the results we show here.

Early in the winter, the rock still retains a substantial amount of heat from the preceding summer (Fig. 3). This results in warmer temperatures for the overall snow-soilrock system and causes the NGR to be slightly higher (about
Table 2. Dependence of TEG on time of the winter, physical properties, terrain geometry and snow depth. TEG is the ratio of maximum calculated growth rate at the peak of the outcrop ("•" in Fig. 1) to the grow th rate in the far field ("O" in Fig. 1)

\begin{tabular}{|c|c|c|}
\hline & $\begin{array}{l}\text { Maximum growth rate } \\
\qquad \mathrm{mm} \mathrm{d}^{-1}\end{array}$ & TEG factor \\
\hline \multicolumn{3}{|l|}{ 2.1. Period during winter } \\
\hline Early & 0.045 & 2.8 \\
\hline Middle (standard) & 0.047 & 2.4 \\
\hline Late & 0.019 & 2.1 \\
\hline \multicolumn{3}{|l|}{ 2.2. Soil thermal properties } \\
\hline Same as snow of standard model & 0.047 & 2.2 \\
\hline Standard model & 0.047 & 2.4 \\
\hline Same as rock of standard model & 0.047 & 1.8 \\
\hline \multicolumn{3}{|l|}{ 2.3. Snow densily $\left(\mathrm{kg} \mathrm{m}^{-3}\right)$} \\
\hline 100 & 0.096 & 2.6 \\
\hline 300 (standard) & 0.047 & 2.4 \\
\hline \multicolumn{3}{|c|}{ 2.4. Snow thermal conductivity ( $\mathrm{Wm}^{-1} K^{-1}$ ) } \\
\hline 0.1 & 0.085 & 2.6 \\
\hline 0.2 & 0.060 & 2.5 \\
\hline 0.3 (standard) & 0.047 & 2.4 \\
\hline \multicolumn{3}{|l|}{ 2.5. Outcrop spacing ( $\mathrm{m}$ ) } \\
\hline 10.0 standard $)$ & 0.047 & 2.4 \\
\hline 3.0 & 0.048 & 2.6 \\
\hline 1.5 & 0.046 & 4.2 \\
\hline \multicolumn{3}{|l|}{ 2.6. Outcrop radius $(m)$} \\
\hline 0.5 standard) & 0.047 & 2.4 \\
\hline 100 & 0.065 & 3.4 \\
\hline \multicolumn{3}{|l|}{ 2.7. Snow-cover depth $(\mathrm{m})$} \\
\hline 1.0 (standard) & 0.047 & 2.4 \\
\hline 0.75 & 0.056 & 2.7 \\
\hline
\end{tabular}

$15 \%$ ) than during the middle of the winter. The calculated absolute growth rate for that time period is slightly erroneous, because the early winter period that we chose was early enough that the model predicts that the temperature at the bottom of the snow cover in an area near the rock is above $0{ }^{\circ} \mathrm{C}$. By moving what we call "early winter" to a slightly later time, this physically unrealistic result would not have occurred. However, the distribution of absolute growth rates would not change significantly, because of offsetting changes in temperature and temperature gradient. The NGRs would be even less sensitive to that correction because, with the decrease of the mean air temperature, the temperature of the whole snow cover is lowered. Thus, the effect is "global", as opposed to a "local" effect seen at just the rock peak or in the far field.

In the late winter, e.g. late February, for a northern alpine snow cover (Fig. 4), the effects are opposite from those observed in early winter. Although the air temperature has begun to warm, the ground has lost much of the heat that had been stored during the preceding summer, and the temperatures in the entire system are lower. This lowers the growth rate everywhere and the growth of depth hoar may stop due to the effects of increasing snow density, decreasing temperature and decreasing temperature gradient. The relative growth rate drops by a disproportionately small amount relative to mid-winter values $12 \%$ in comparison to $60 \%$ for absolute growth rates), because the combined effects of temperature and temperature gradient are only slightly more influential near the peak of the rock than in the far field. 

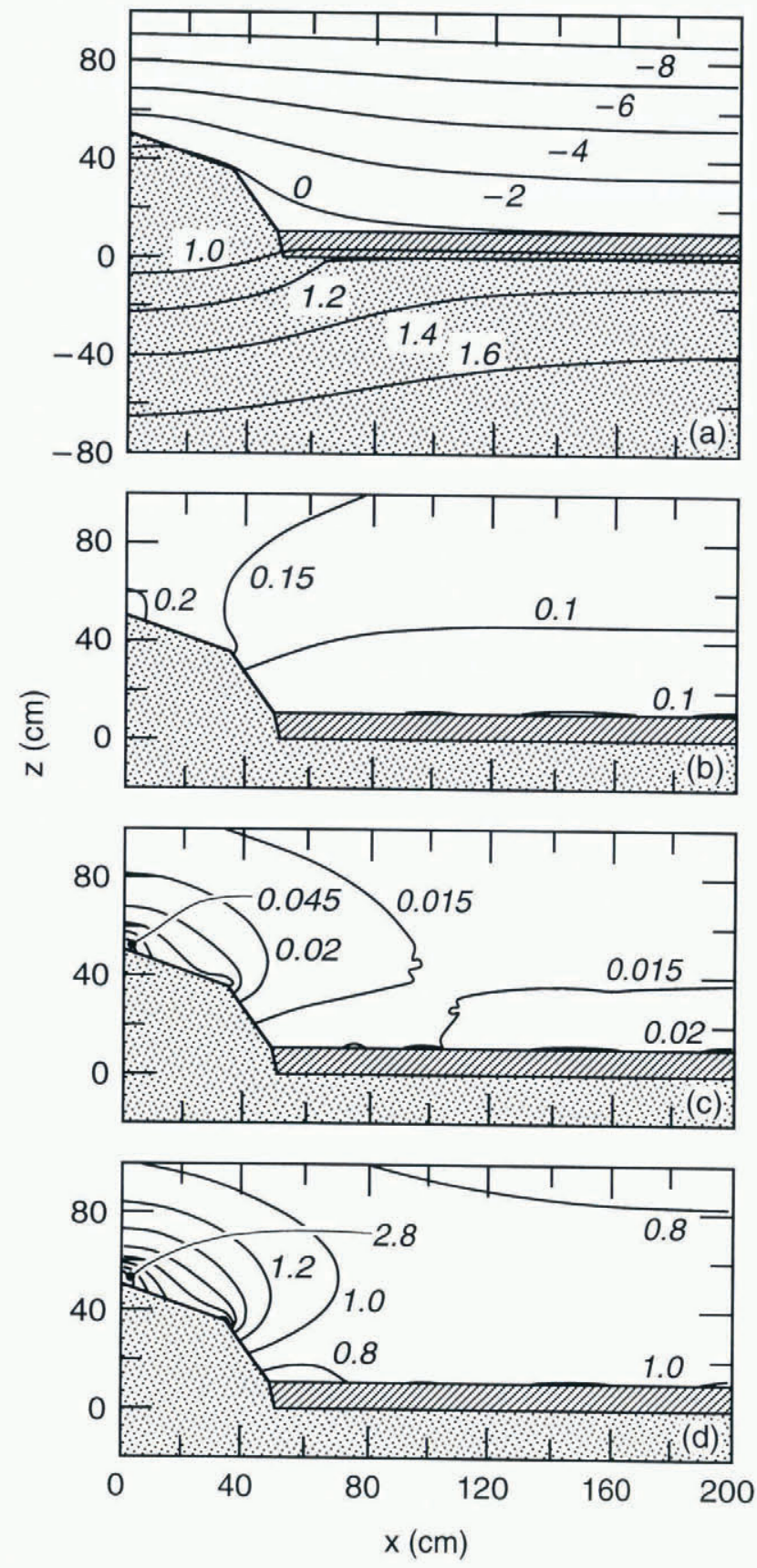

Fig. 3. (a) Temperature, (b) temperature gradient, (c) growth rate and (d).NGR for a standard snow cover in an early winter thermal regime. The above-freezing temperatures at the foot of the outcrop are not physically meaningful, since the snow would melt and melting is not allowed in the model. However, the results are affected little by this.

\section{PHYSICAL PROPERTIES}

\section{Soil conductivity}

The thermal properties of the soil had virtually no effect on the absolute growth rates near the peak of the rock. However, they did have an effect on the growth rates in the far field, particularly near the base of the snow (Table 2.2). The soil of the standard model, estimated using correlations discussed by Farouki (1981, p. 105), is slightly less thermally conductive than the snow in that model. This corresponds to a dry, sandy soil (or, alternatively, a layer of moist organic soil that is overlain by dormant grass). Therefore, when the soil is replaced by snow that is identical to that which comprises the snow cover, the vertical heat flow in the far field is
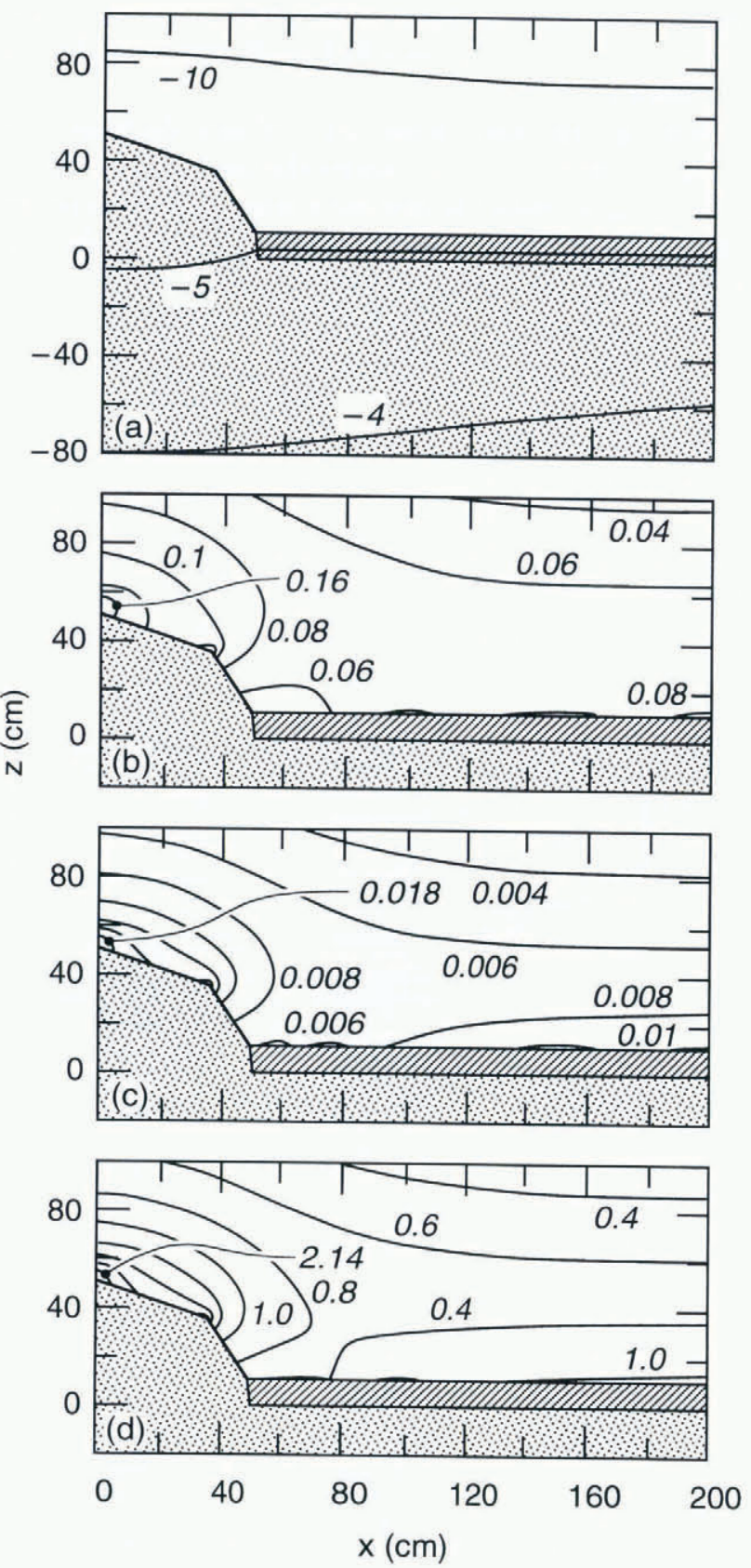

Fig. 4. (a) Temperature, (b) temperature gradient, (c) growth rate and (d) NGR for a standard snow cover in a late-winter thermal regime.

increased relative to the standard model and the far-field crystal growth rate increases slightly.

When the soil of the standard model is assigned the thermal properties of the rock, the far-field vertical heat flow increases substantially and reduces TEG by about $25 \%$ in comparison with the standard model. The thin layer of unconsolidated material thus contributes to TEG but the contribution is small in comparison to the effect of the terrain geometry.

\section{Snow density}

The snow density in the standard model, $300 \mathrm{~kg} \mathrm{~m}^{-3}$, is typical of a mature dry maritime snow cover, although maritime snow covers typically have melt features in Nature (Sturm and others, 1995). Snow in high-altitude alpine regions, in which depth hoar is more likely to arise, usually has a lower density than the standard model. This is particularly true for thin snow covers in continental mountain 
ranges, where the density of snow in a mature snow cover might be expected to be two-thirds of the density of the standard model.

Since the thermal conductivity of snow decreases with decreasing density, we compared the standard model to a model in which the snow density was changed to a very low value of $100 \mathrm{~kg} \mathrm{~m}^{-3}$ and assigned it a thermal conductivity of $0.07 \mathrm{~W} \mathrm{~m}^{-1} \mathrm{~K}^{-1}$ using estimates from published data (Sturm and Johnson, 1992). The growth rate at the peak of the rock doubled as a result of reducing the snow density to this value (Table 2.3). However, TEG increased only $9 \%$ over the standard model. The increase in the insulation of the snow cover resulted in increases in both the temperature and temperature gradient at the bottom of the snow (Fig. 5). This effect occurred both at the rock peak and in the far field. The combination of these two effects was stronger near the peak but the small increase in TEG with the lower den-
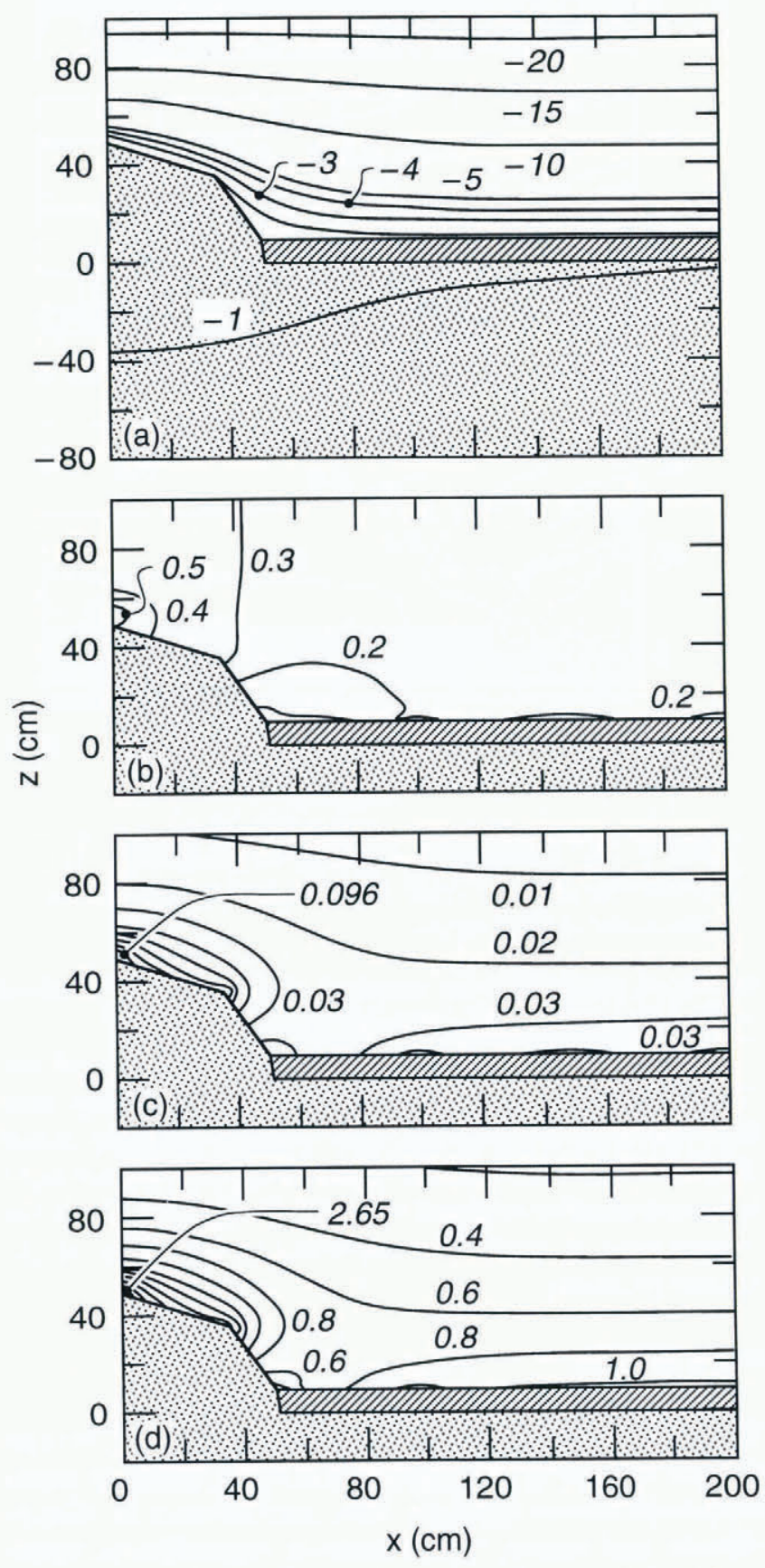

Fig. 5. (a) Temperature, (b) temperature gradient, (c) growth rate and (d) NGR for a snow cover of density $100 \mathrm{~kg} \mathrm{~m}^{3}$. sity indicates that the far field also responded strongly to the change. Thus, a greater percentage of the entire snow cover would metamorphose to depth hoar, because of the higher growth rates.

\section{Snow conductivity}

For snow having a density of $300 \mathrm{~kg} \mathrm{~m}^{-3}$, published values of thermal conductivity range from 0.05 to $0.4 \mathrm{~W} \mathrm{~m}^{-1} \mathrm{~K}^{-1}$. We investigated the effects of different types of snow on TEG by selecting a range of thermal conductivity that would correspond to a range of microstructural characteristics of the snow (Table 2.4). The standard snow represents the highest conductivity in the range that corresponds to its density. Decreasing the conductivity to the low end of the range $\left(0.1 \mathrm{~W} \mathrm{~m}^{-1} \mathrm{~K}^{-1}\right)$ increased the absolute growth rate at the peak of the rock by $80 \%$, while it increased the relative growth rate by only $10 \%$. The temperature distribution and the growth rates responded in a manner that is similar to the case of decreasing the snow density, as expected, but this indicates that microstructural characteristics other than density can play a strong role in the variation of crystalgrowth rates in a snow cover. For example, as depth hoar forms, the thermal conductivity of the snow could change without a measurable change in density.

\section{TERRAIN GEOMETRY}

\section{Rock spacing}

The lateral boundaries of the solution region have prescribed zero heat flux, since they are planes of symmetry. In the standard model, the width of the solution space was $5 \mathrm{~m}$. This corresponds to a center-to-center rock spacing of $10 \mathrm{~m}$. For the standard model, this distance is sufficient to prevent the interaction of thermal fields between neighboring rocks. This is supported by the result that the temperature fields at the mid-point between the rocks do not begin to respond to changes in the rock distance until the rock separation is decreased to about $3 \mathrm{~m}$ (Table 2.5). Strong effects are observed when the separation is decreased to $1.5 \mathrm{~m}$ (Fig. 6), or three rock radii.

Unexpectedly, the absolute growth rates at the rock peak were largely unaffected by the rock spacing. As the rocks are moved closer together, the most dramatic response that occurs is that the growth rate in the far field, now the valley between the rock peaks, decreases by nearly a factor of 2 in comparison to the standard, or non-interacting, model. It appears that the rock outcrops are acting like cooling fins and heat, that would otherwise flow into the snow at the soil mid-point, is diverted along the more conductive route through the outcrop. As the rocks are drawn together, there is an increasing fraction of the total area that is influenced by the thin snow layer over the outcrop and the more highly conductive rock pathway. Thus, while the growth rate drops, the volume of depth hoar still increases.

\section{Snow depth}

When the snow depth is of the same order as the outcrop height, it affects both the absolute growth rates and NGRs (Table 2.7), but the NGRs increased more slowly with decreasing depths than did the absolute rates. While the far field was affected by the change in snow depth, the region near the rock peak was more sensitive to the change. The 

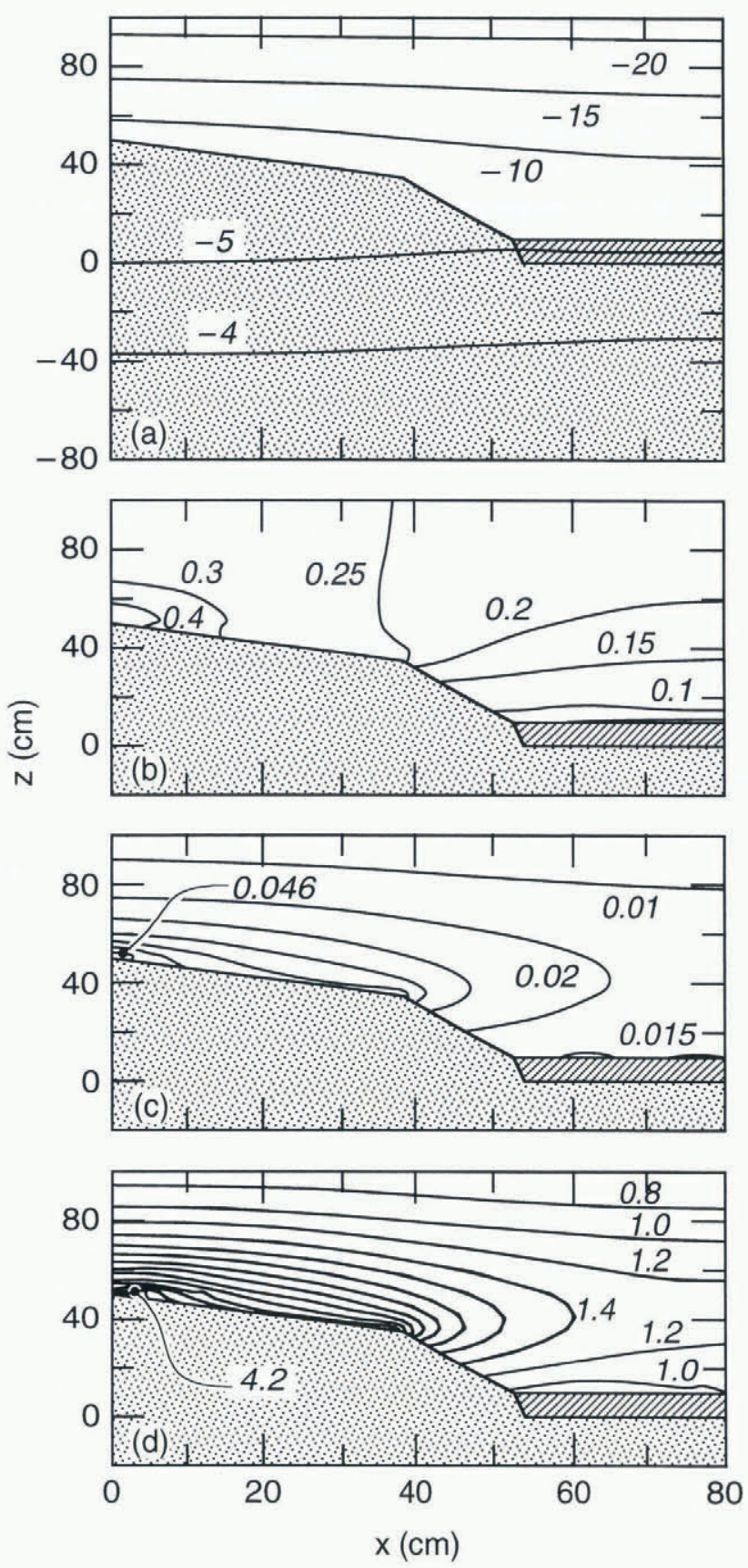

Fig. 6. (a) Temperature, (b) temperature gradient, (c) growth rate and (d) NGR for a center-to-center rock spacing of $1.5 \mathrm{~m}$.

thinner snow cover caused the region around the rock peak to be slightly cooler than in the standard model but the heat flux in that region was nearly twice as high. The temperature-gradient effect dominated the slight cooling effect and boosted the absolute growth rates there (Fig. 7). In fact, given the magnitudes of the calculated temperature gradients, this is a good example of when we might get rapid depth-hoar growth over the rock but no depth-hoar growth away from the rock.

The bulk thermal resistance of the snow cover in that region was approximately halved by reducing the snow depth from 1.0 to $0.75 \mathrm{~m}$, because the snow immediately over the $0.5 \mathrm{~m}$ rock was only $0.5 \mathrm{~m}$ deep in the standard model. For shallow snow covers, then, even considering two-dimensional flow, the heat flux is approximately inversely proportional to the snow depth. While the thinner snow cover also caused cooling in the far field, the relative growth rate responded to the thinning of the snow cover, so it is clear
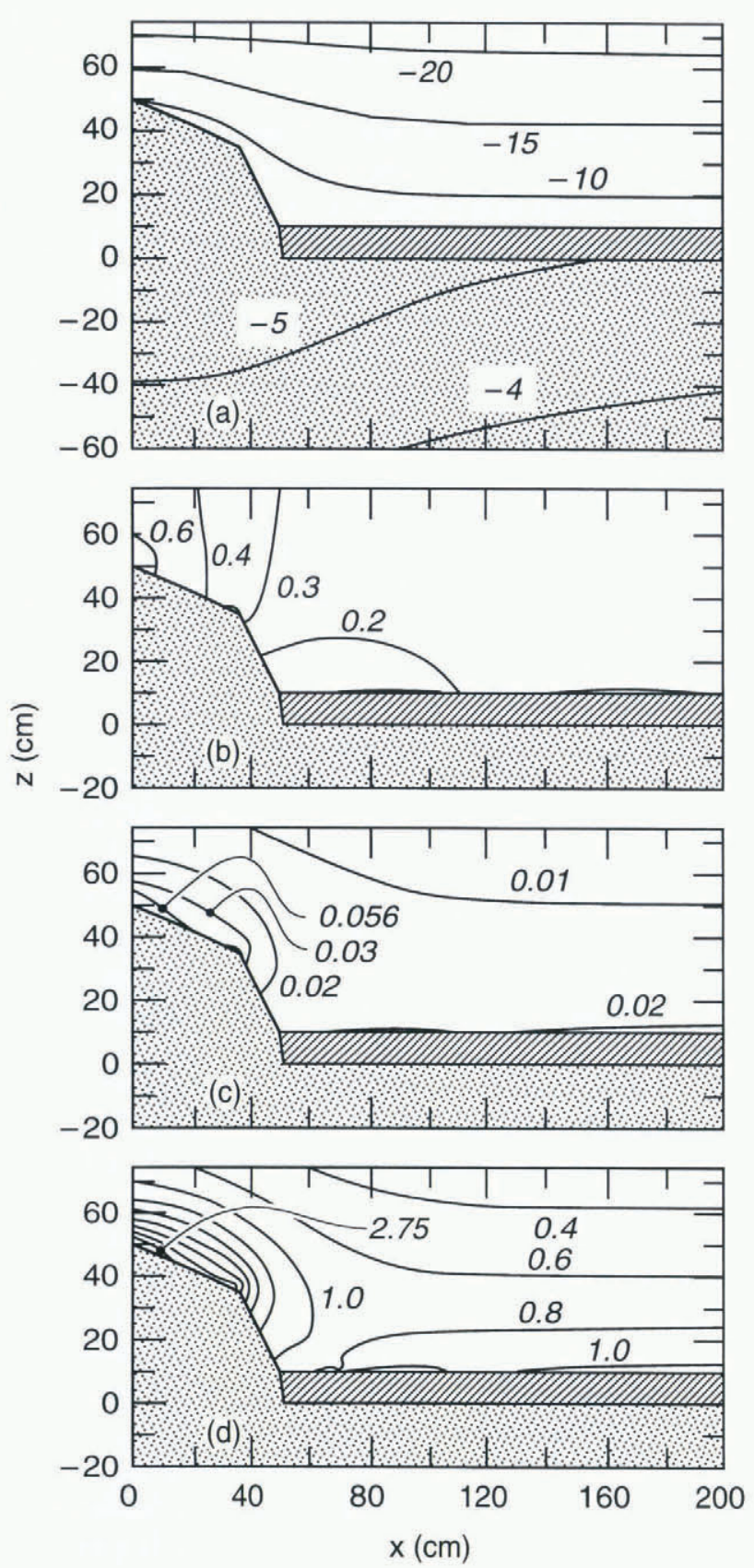

Fig. 7. (a) Temperature, (b) temperature gradient, (c) growth rate and (d) NGR for a snow cover of $0.75 \mathrm{~m}$ depth.

that the terrain influenced the distribution of temperature and temperature gradients in an uneven manner.

\section{DISGUSSION AND CONGLUSIONS}

In Nature, the thermal properties of the snow cover would change as grains grow and the grain population matures (Arons, 1994). In this study, such feed-backs have been ignored in the interest of exploring first-order topographic effects. However, the growth of depth hoar has been linked theoretically to a decrease in thermal conductivity by Arons (1994), and Sturm and Johnson (1992) observed this relationship in the field. The tendency for depth hoar to act as a greater thermal insulator than the surrounding snow might have a self-limiting effect on TEG.

This simple model illustrates that variations in season, snow properties, ground-cover properties, outcrop-aspect ratio, outcrop spacing and snow depth may cause a two- to four-fold increase in depth-hoar growth rates in comparison 
to rates far from rock outcrops. Higher estimates of TEG are associated with an early-season thermal regime, the presence of a layer of insulating soil, low-density snow, close outcrop spacing, expansive outcrops and thin snow cover.

The greatest value of TEG, 4.2, was observed by decreasing the center-to-center distance of the outcrops to $1.5 \mathrm{~m}$. This is accomplished by a decrease in the far-field growth rates rather than an increase in the growth rates near the peak of the outcrop, because all of the far field is affected by the rock, i.e. there is no longer a "far field". Normally, the thermal conductivity of the soil tends to regulate the growth rate in the far field, while the growth rate near the outcrop is highly influenced by the proximity of the rock. Therefore, variations in terrain features may contribute to the spatial heterogeneity of depth hoar by suppressing growth in the "background", while leaving it unchanged over salient features.

The spatial variation in the growth of depth hoar is shown clearly in Figures 3, 4 and 6, where for a critical temperature gradient of $0.1^{\circ} \mathrm{C} \mathrm{m}^{-1}$, depth hoar would grow over the rock but not over the soil. This spatial variation in the growth of depth hoar also occurs in parts of Figures 2, 5 and 7 , but to a lesser extent, since there would be some depth-hoar growth over the soil in these cases. However, in all of these cases, it is clear that the results obtained from a test pit dug over the soil would certainly be significantly different from the results obtained from a test pit over the rock.

Greater changes in the near-rock absolute growth rates were observed to coincide with less extreme TEGs. This indicates that these changes were associated with more global perturbations of the standard model. For example, the late-season snow cover is everywhere colder than in the standard model, so growth suppression in the far field nearly kept pace with that near the rock peak. The effects of snow density, thermal conductivity and thickness were also more global, since they all regulate the overall temperature of the snow cover.

The relative importance of spatial variation of snow depth vs the spatial variation of thermal-conductivity contrast between rock and snow is still unknown. In particular, when the horizontal extent of the outcrop was stretched to $100 \mathrm{~m}$, almost all of the TEG can be attributed to increased growth near the rock peak. It is not clear whether the diminished snow thickness near the rock peak or the increased heat channeling through the highly conductive rock dominates this effect.

Practitioners have recognized the importance of the geometry of the snow-ground interface in the distribution of depth-hoar growth rates. These results help to explain that relationship. Additional work needs to be done to further iso- late the effects of snow depth from TEG and to improve our ability to describe the snow-ground interface in a manner that will enable us to apply knowledge of TEG to specific locations. Eventually, this could improve our ability to assess avalanche hazards using geomorphologic and climatological data. Further improvements should include the effects of time-varying snow density, thermal conductivity, grain-size distribution and other textural quantities.

\section{ACKNOWLEDGEMENTS}

We thank Drs J. Lever and B. Davis for useful reviews of the manuscript and Dr M. Sturm for very helpful editorial comments. This work began with a visit to an avalanche site, courtesy of Dr B. Jamieson and M. Wiegele. The work was funded by the In-House Laboratory Independent Research Program at U.S. Army CRREL and work unit AT24-SCSO1.

\section{REFERENCES}

Akitaya, E. 1974. Studies on depth hoar. Contrib. Inst. Low Temp. Sci., Ser. A 26. Arons, E. M. 1994. Dependence of snow thermal and electrical conductivities on microstructure. (Ph.D. thesis, Dartmouth College.)

Arons, E. M. In press. Physics of slab avalanches. CRREL Monogr.

Bird, R. B., W. E. Stewart and E. N. Lightfoot. 1960. Transport phenomena. New York, etc., John Wiley and Sons.

Brun, E., P. David, M. Sudul and G. Brunot. 1992. A numerical model to simulate snow-cover stratigraphy for operational avalanche forecasting. j. Glaciol., 38 (128), $13-22$.

Colbeck, S. C. 1983. Theory of metamorphism of dry snow. J. Geophys. Res., 88 (C9), 5475-5482.

Farouki, O.T. 1981. Thermal properties of soils. CRREL Monogr. 81-1.

Gray, J. M. N. T., L.W. Morland and S. C. Colbeck. 1995. The effect of change in thermal properties on the propagation of a periodic thermal wave: application to a snow-buried rocky outcrop. f. Geophys. Res., 100 (B8), 15,267-15,279.

Gubler, H. 1985. Model for dry snow metamorphism by interparticle vapor flux. f. Geophys. Res., 90 (D5), $8081-8092$.

Jamieson, J. B. and C. D. Johnston. 1994. Monitoring a shear frame stability index and skier-triggered slab avalanches involving persistent snowpack weaknesses. In ISSW'94. International Snow Science Workshop, 30 October-3. November 1994, Snowbird, Ulah. Proceedings. Snowbird, UT, P.O. Box 49, 14-21.

Jordan, R. 1991. A one-dimensional temperature model for a snow cover: technical documentation for SNTHER M.89. CRREL Spec. Rep. 91-16.

Logan, N. 1993. Snow temperature patterns and artificial avalanche release. In Armstrong, R., ed. ISSW'92. A Merging of Theory and Practice. International Snow Science Workshop, 4 8 October 1992, Breckenridge, Colorado. Proceedings. Denver, CO, Avalanche Information Center, 37-46.

Sewell, G. 1993. PDE2D: easy-to-use software for general two-dimensional partial differential equations. Adv. Engin. Software, 17, 105-112.

Sturm, M., J. Holmgren and G. E. Liston. 1995. A seasonal snow cover classification scheme for local to global applications. 7. Climate, 8 (5), Part 2, 1261-1283.

Sturm, M. and J. B. Johnson. 1992. Thermal conductivity measurements of depth hoar. J. Geophys. Res., 97 (B2), 2129-2139. 